\title{
Differential diagnosis of solitary fibrous tumors: A study of 454 soft tissue tumors indicating the diagnostic value of nuclear STAT6 relocation and ALDH1 expression combined with in situ proximity ligation assay
}

\author{
SHAIDA OULADAN ${ }^{1 *}$, MARCEL TRAUTMANN $^{2 *}$, ELIAS OROUJI $^{3}$, WOLFGANG HARTMANN $^{2}$, \\ SEBASTIAN HUSS $^{2}$, REINHARD BÜTTNER ${ }^{1}$ and EVA WARDELMANN ${ }^{2}$ \\ ${ }^{1}$ Department of Pathology, University Hospital Cologne, Cologne; ${ }^{2}$ Gerhard-Domagk-Institute of Pathology, \\ University Hospital Muenster, Muenster; ${ }^{3}$ Skin Cancer Unit, German Cancer Research Center (DKFZ), Heidelberg, Germany
}

Received February 18, 2015; Accepted April 2, 2015

DOI: 10.3892/ijo.2015.2975

\begin{abstract}
Solitary fibrous tumors (SFTs) are rare mesenchymal neoplasms, displaying variable morphological and clinicopathological features. Supportive immunohistochemical markers such as CD34, CD99, BCL2 and LSD1 are commonly applied in the differential diagnosis of SFTs, although none is sufficiently sensitive or specific enough. The aim of the present study was to examine the most differential markers for the reliable distinction of SFTs from histological mimics. We investigated the expression of STAT6, NAB2, ALDH1, GRIA2 and IGF2 in 454 comprehensive soft tissue tumors, comprising formalin-fixed paraffin-embedded (FFPE) tissue samples from 80 SFTs and 374 other mesenchymal tumors. The Duolink in situ proximity ligation assay (PLA) was adopted for the detection of NAB2-STAT6 fusion proteins. STAT6 was expressed in all 80 SFT cases with a moderate-strong nuclear staining intensity. In contrast, only 4/374 (1\%) non-SFT mesenchymal tumors showed a nuclear STAT6 staining pattern. Strong expression of NAB2 and IGF2 was detected in SFT and non-SFT cases. Positive GRIA2 immunoreactivity was found in 64\% (SFT) and 8\% (non-SFT), respectively. Expression of ALDH1 was moderate-strong in $76 \%$ (SFT), whereas only 2 non-SFT lesions showed positive ALDH1 immunoreactivity. Moreover, the presence of NAB2-STAT6 fusion proteins was indicated in 71/78 (91\%) SFT cases by PLA. Nuclear STAT6 and cytoplasmic ALDH1 expression are the most sensitive
\end{abstract}

Correspondence to: Dr Eva Wardelmann, Gerhard-DomagkInstitute of Pathology, University Hospital Muenster, AlbertSchweitzer-Campus 1, Building D17, Domagkstrasse 17, D-48149 Muenster, Germany

E-mail: eva.wardelmann@ukmuenster.de

*Contributed equally

Key words: solitary fibrous tumor, STAT6, NAB2, ALDH1, GRIA2, Duolink in situ proximity ligation assay and specific markers in the differential diagnosis of SFTs. Furthermore, application of Duolink in situ proximity ligation assay can be helpful to detect the NAB2-STAT6 fusion protein in the majority of SFTs.

\section{Introduction}

Solitary fibrous tumor (SFT) is a mesenchymal tumor which can arise from any organ in the body with no gender preference (1-3). According to the WHO classification (2013), SFTs are classified as tumors with intermediate malignancy and rarely metastatic potential (4). Some characteristics of aggressiveness including tumor size $>15 \mathrm{~cm}$, age $>55$ years and mitotic index $>4 / 10$ high power fields (HPF) are shown to increase the risk of metastasis and mortality (5). The most efficient treatment is complete resection of tumor bulk with adequate margins. To date, no adjuvant treatment strategy exists due to the resistance of tumor cells to chemo- and radiotherapy (6-8).

Histologically, establishment of SFT diagnosis can be challenging as immunohistochemical markers such as CD34, BCL2 or CD99 are widely expressed in a variety of other soft tissue tumors and neither is sensitive nor specific enough. Furthermore, the more or less characteristic morphology with hyper- and hypocellular areas of fibroblast-like cells in a so-called pattern less architecture can occur in a large number of non-SFTs. This is also true for the so-called hemangiopericytoma-like vascular pattern which consists of plenty of branching vessels with a staghorn pattern (4). Because of the existence of several tumor entities which may exhibit a 'hemangiopericytoma'-like architecture, the designation 'hemangiopericytoma' has now been deleted in the current WHO classification from 2013 (4). Common diagnostic pitfalls of SFTs are other spindle cell lesions such as gastrointestinal stromal tumors, vascular neoplasia or dedifferentiated liposarcomas.

Recently, a recurrent cytogenetic alteration has been identified in the vast majority of SFTs, leading to the specific gene fusion of NAB2 and STAT6 $(9,10)$. NAB2 is a transcriptional modulator of zinc finger transcription factors and located in 
the nucleus $(11,12)$. STAT6 is involved in activation of transcription and in IL4-mediated biological responses. It is a cytoplasmic protein which can be phosphorylated by receptor associated kinases, resulting in relocation to the nucleus (13). The NAB2-STAT6 gene fusion product leads to the enhanced expression of EGR1 (early growth response 1) targeted genes such as IGF2 (10). Furthermore, GRIA2 has been reported as the top upregulated gene in a whole gene expression study of SFTs (14). Another upregulated protein is ALDH1 which has been shown to be a potential diagnostic marker of meningeal SFTs and hemangiopericytoma (HPC) (15).

As correct diagnosis of SFTs is still challenging due to the lack of reliable tumor markers, in the present study we aimed at identifying diagnostically relevant markers, facilitating the differential diagnosis. We investigated the expression of STAT6, NAB2, ALDH1, GRIA2 and IGF2 by immunohistochemistry. In addition, we established the Duolink in situ proximity ligation assay (PLA) to identify the recurrent NAB2STAT6 gene fusion product at protein level and explored the correlation between the presence of this specific gene fusion and the immunohistochemical positivity of nuclear STAT6 and NAB2.

\section{Materials and methods}

Retrieval of tumor samples. To constitute a comprehensive tumor collection, we retrospectively analyzed our archives at the Department of Pathology (Cologne) and the GIST and Sarcoma Registry (Cologne/Bonn, 19942012) for following diagnoses: solitary fibrous tumor (SFT) and hemangiopericytoma (HPC). We initially retrieved 106 formalin-fixed paraffin-embedded (FFPE) tumor samples. Due to the lack of remaining FFPE material, 8 samples had to be excluded from further analyses. According to the current WHO classification of tumors, all SFT diagnoses have been reviewed and re-evaluated by two experienced pathologist based on standard morphological criteria, immuno/histopathological and in selected cases, corroborative molecular procedures. In summary, 80 comprehensive SFT cases were included in the present study and 18 cases had to be excluded due to re-classification ( 35 women, 45 men; median age at diagnosis, 59.5 years; range, 21-92 years; median tumor size, $8 \mathrm{~cm}$; range, 0.8-25 cm; summarized in Table I). Overall, tissue samples were excisions from various anatomic locations including: abdomen ( $n=16)$, extremities $(n=3)$, head and neck $(n=10)$, lung $(n=8)$, mesenterium $(n=4)$, pelvis $(n=8)$, pleura $(n=19)$, prostate $(n=6)$, retroperitoneum $(n=2)$ and thorax $(n=4)$. Individual clinicopathological characteristics are summarized in Table II. The study was approved by the local Ethics Committee and conducted in accordance with current ethical standards (Declaration of Helsinki, 1975).

Tumor microarrays (TMAs). To examine the specificity (SP) and sensitivity (SE) of various diagnostic markers, we used 12 different TMAs (each FFPE tumor tissue block with at least two representative 1-mm cores) constructed in our collaborative research group (Competence network for sarcomas, KoSar). Overall, 385 non-SFT mesenchymal tumors were represented: angiosarcomas $(\mathrm{AS} ; \mathrm{n}=29)$, dedifferentiated liposarcomas (DDLS; $n=74$ ), hemangiomas $(n=6)$, leiomyo-
Table I. Distribution and clinicopathological characteristics of patients with solitary fibrous tumors.

\begin{tabular}{lc}
\hline Characteristics & Total $(\mathrm{n}=80)$ \\
\hline Age (years) & \\
Mean $( \pm$ SD) & $58.4( \pm 16.1)$ \\
Median (range) & $59.5(21-92)$ \\
$<58$ & $36(45 \%)$ \\
$\geq 58$ & $44(55 \%)$ \\
Gender & \\
Female & $35(44 \%)$ \\
Male & $45(56 \%)$ \\
Size $(\mathrm{cm})$ & \\
Mean $( \pm$ SD) & $8.2( \pm 5.3)$ \\
Median (range) & $8( \pm 0.8-25)$ \\
$<8$ & $32(40 \%)$ \\
$\geq 8$ & $33(41 \%)$ \\
ND & $15(19 \%)$ \\
Anatomic location & \\
Abdomen & 16 \\
Extremities & 3 \\
Head and neck & 10 \\
Lung & 8 \\
Mesenterium & 4 \\
Pelvis & 8 \\
Pleura & 19 \\
Prostate & 6 \\
Retroperitoneum & 2 \\
Thorax & 4 \\
\hline
\end{tabular}

$\mathrm{ND}$, not determined.

sarcomas (LMS; $\mathrm{n}=70$ ), malignant peripheral nerve sheath tumors (MPNST; $n=24$ ), myxoid liposarcomas (MLS; $n=29$ ), pleomorphic liposarcomas (PLS; $n=11)$, schwannomas $(n=12)$, synovial sarcomas ( $\mathrm{SS} ; \mathrm{n}=16)$, undifferentiated pleomorphic sarcomas (UPS; $n=36$ ) and well-differentiated liposarcomas (WDLS; $\mathrm{n}=78$ ). Selected tumor areas were confirmed by two experienced pathologists before and after TMA construction.

Immunohistochemistry (IHC). STAT6 (polyclonal rabbit, clone S-20, C-terminal epitope, 1:800, sc-621) and NAB2 (monoclonal mouse, clone 1C4, 1:200, sc-23867) antibodies were purchased from Santa Cruz Biotechnology (Santa Cruz, CA, USA), GRIA2 (monoclonal rabbit, clone EP929Y, 1:100, ab-52896) and IGF2 antibodies (polyclonal rabbit, 1:200, ab-9574) from Abcam (Cambridge, UK) and ALDH1 antibody (mouse IgG1, clone 44/ALDH1, 611195) from BD Transduction Laboratories (San Jose, CA, USA). Immunohistochemical staining was performed with a Lab Vision 480S Autostainer (Thermo Fisher Scientific, Waltham, MA, USA) on $4-\mu \mathrm{m}$ sections from FFPE whole tissue and/or TMA blocks. In brief, the staining procedure included: i) heat-induced epitope retrieval (HIER) pretreatment using citrate buffer ( $\mathrm{pH} 6.0$; NAB2, IGF2 and ALDH1) or EDTA (pH 8.0; STAT6 and 
Table II. Clinicopathological characteristics and immunohistochemical results of 80 solitary fibrous tumors.

\begin{tabular}{|c|c|c|c|c|c|c|c|c|c|c|c|c|c|}
\hline \multirow[b]{2}{*}{ No. } & \multirow[b]{2}{*}{$\begin{array}{l}\text { Age (years)/ } \\
\text { gender }\end{array}$} & \multirow[b]{2}{*}{$\begin{array}{l}\text { Tumor } \\
\text { location }\end{array}$} & \multirow[b]{2}{*}{$\begin{array}{l}\text { Size } \\
(\mathrm{cm})\end{array}$} & \multicolumn{9}{|c|}{ Immunohistochemistry (proportion score) } & \multirow{2}{*}{$\begin{array}{c}\text { Duolink } \\
\text { in situ } \\
\text { PLA }\end{array}$} \\
\hline & & & & $\begin{array}{c}\text { STAT6 } \\
\text { (nuclear) }\end{array}$ & $N A B 2$ & $C D 34$ & $A L D H 1^{\mathrm{a}}$ & $G R I A 2^{\mathrm{a}}$ & $I G F 2^{\mathrm{a}}$ & $C D 99$ & $B C L 2$ & $L S D 1$ & \\
\hline 1 & $53 / \mathrm{F}$ & Pelvis & 6 & 5 & 5 & 5 & 5 & $5^{\mathrm{b}}$ & $5^{\mathrm{b}}$ & 5 & $3^{\mathrm{b}}$ & 5 & + \\
\hline 2 & 49/M & Extremities & 3 & 4 & 4 & 5 & $4^{\mathrm{b}}$ & 0 & 5 & 5 & $4^{\mathrm{b}}$ & 5 & + \\
\hline 3 & $30 / \mathrm{F}$ & Thorax & 5 & 5 & 5 & 5 & 0 & 5 & 5 & 5 & 3 & 5 & + \\
\hline 4 & $28 / F$ & Abdomen & 20 & 5 & 5 & 5 & 5 & $5^{\mathrm{b}}$ & 0 & 0 & 5 & 5 & - \\
\hline 5 & $58 / \mathrm{F}$ & Pleura & 8 & 4 & 4 & 5 & $4^{\mathrm{b}}$ & $5^{\mathrm{b}}$ & 5 & $3^{\mathrm{b}}$ & 4 & 5 & + \\
\hline 6 & $59 / \mathrm{F}$ & Head and neck & 4 & 5 & 5 & 5 & 0 & $5^{\mathrm{b}}$ & 5 & 1 & 4 & 4 & + \\
\hline 7 & $44 / \mathrm{F}$ & Abdomen & 10 & 4 & 3 & 5 & 5 & $5^{\mathrm{b}}$ & $5^{\mathrm{b}}$ & 0 & 4 & 5 & - \\
\hline 8 & $37 / \mathrm{M}$ & Mesenterium & 11 & 4 & 4 & 4 & 5 & $5^{\mathrm{b}}$ & 5 & 3 & 0 & 3 & + \\
\hline 9 & $68 / \mathrm{M}$ & Abdomen & 11 & 3 & 4 & 5 & 5 & 5 & 5 & 0 & 5 & 5 & + \\
\hline 10 & $47 / \mathrm{M}$ & Abdomen & 10 & 3 & 5 & 5 & 0 & 0 & $4^{b}$ & 0 & 4 & $3^{b}$ & + \\
\hline 11 & $67 / \mathrm{M}$ & Lung & 0.9 & 4 & 5 & 4 & ND & ND & ND & 3 & 2 & 5 & + \\
\hline 12 & $70 / \mathrm{M}$ & Prostate & ND & 5 & 5 & 3 & ND & ND & ND & 4 & 4 & 4 & + \\
\hline 13 & $51 / \mathrm{F}$ & Pleura & 3 & 5 & 5 & $3^{\mathrm{b}}$ & 5 & 5 & 5 & 0 & 5 & $4^{b}$ & + \\
\hline 14 & $72 / \mathrm{F}$ & Head and neck & 1.5 & 5 & 5 & 5 & ND & ND & ND & $3^{\mathrm{b}}$ & 4 & 5 & + \\
\hline 15 & $49 / \mathrm{M}$ & Extremities & 5.5 & 5 & 5 & 3 & ND & ND & ND & 0 & $4^{b}$ & 5 & + \\
\hline 16 & $73 / \mathrm{F}$ & Head and neck & 4.5 & 5 & 5 & 5 & 5 & 5 & 5 & 0 & 5 & 5 & + \\
\hline 17 & $52 / \mathrm{M}$ & Lung & 2.5 & 5 & 5 & 5 & 5 & 5 & 5 & 3 & 4 & 5 & + \\
\hline 18 & $40 / \mathrm{F}$ & Pleura & 4 & 5 & 5 & 5 & 5 & 5 & 5 & 1 & 5 & 4 & + \\
\hline 19 & $66 / F$ & Pleura & 3.5 & 4 & 5 & 5 & $3^{\mathrm{b}}$ & 5 & 5 & 1 & 4 & 5 & + \\
\hline 20 & $76 / \mathrm{M}$ & Abdomen & 3.7 & 5 & 5 & 5 & $4^{\mathrm{b}}$ & $5^{\mathrm{b}}$ & $5^{\mathrm{b}}$ & 5 & 0 & 5 & + \\
\hline 21 & $48 / \mathrm{F}$ & Retroperitoneum & 10 & 4 & 5 & 5 & 5 & 4 & 3 & 4 & $3^{\mathrm{b}}$ & 5 & + \\
\hline 22 & $71 / \mathrm{M}$ & Prostate & ND & 5 & 5 & 4 & 5 & 5 & 5 & 5 & 5 & 5 & + \\
\hline 23 & $64 / \mathrm{M}$ & Prostate & ND & 4 & 5 & 5 & ND & ND & ND & 5 & 4 & 4 & + \\
\hline 24 & $64 / \mathrm{M}$ & Prostate & ND & 5 & 5 & 4 & 5 & 5 & 5 & 2 & 4 & 5 & + \\
\hline 25 & $59 / \mathrm{M}$ & Pleura & ND & 4 & 5 & 3 & 5 & 5 & 5 & 5 & 1 & 5 & + \\
\hline 26 & $64 / \mathrm{M}$ & Pelvis & ND & 3 & 4 & 5 & 5 & 5 & 5 & 3 & 2 & 5 & + \\
\hline 27 & $64 / \mathrm{M}$ & Pleura & 23 & 5 & 5 & 5 & ND & ND & ND & 5 & 5 & 5 & - \\
\hline 28 & $51 / \mathrm{F}$ & Lung & 5 & 5 & 5 & 5 & ND & ND & ND & 2 & 5 & 4 & ND \\
\hline 29 & 29/M & Head and neck & 0.8 & 5 & 5 & 2 & ND & ND & ND & 5 & 4 & 5 & + \\
\hline 30 & $29 / \mathrm{M}$ & Head and neck & 5 & 5 & 5 & 2 & 5 & 5 & 4 & 5 & 4 & 5 & + \\
\hline 31 & $51 / \mathrm{F}$ & Pleura & 12 & 5 & 4 & 5 & 5 & 5 & 5 & $3^{\mathrm{b}}$ & 5 & 5 & + \\
\hline 32 & $82 / F$ & Pleura & 25 & 4 & 5 & 5 & 5 & 5 & $5^{\mathrm{b}}$ & $4^{b}$ & 5 & 5 & - \\
\hline 33 & $42 / \mathrm{F}$ & Pleura & 11 & 4 & 4 & 5 & 5 & $3^{\mathrm{b}}$ & 5 & $4^{b}$ & 5 & 5 & + \\
\hline 34 & $52 / \mathrm{M}$ & Pleura & 8 & 5 & 5 & 5 & 5 & 5 & 5 & 2 & 4 & 4 & + \\
\hline 35 & $36 / F$ & Thorax & 12 & 4 & 4 & 4 & 5 & 5 & 5 & 1 & 5 & 4 & + \\
\hline 36 & $56 / \mathrm{M}$ & Pleura & 5 & 4 & 4 & 2 & 5 & 5 & 5 & 2 & 5 & 4 & + \\
\hline 37 & $70 / \mathrm{F}$ & Abdomen & 17 & 3 & 3 & 2 & 5 & 2 & $5^{\mathrm{b}}$ & 3 & 1 & 5 & - \\
\hline 38 & $57 / \mathrm{M}$ & Abdomen & 8 & 5 & 5 & 3 & ND & ND & ND & 5 & 2 & $3^{b}$ & + \\
\hline 39 & $53 / \mathrm{M}$ & Abdomen & 10 & 3 & 3 & 3 & ND & ND & ND & 0 & 1 & 4 & + \\
\hline 40 & $66 / \mathrm{M}$ & Mesenterium & 13 & 5 & 4 & 5 & 1 & 5 & 5 & 4 & 3 & 4 & - \\
\hline 41 & $84 / \mathrm{M}$ & Abdomen & 11 & 4 & 5 & 4 & ND & ND & ND & 5 & 0 & 5 & + \\
\hline 42 & $71 / \mathrm{M}$ & Mesenterium & ND & 3 & 3 & 4 & 5 & 0 & $5^{\mathrm{b}}$ & 0 & 0 & 4 & + \\
\hline 43 & $57 / \mathrm{M}$ & Prostate & ND & 4 & 5 & 5 & 5 & 5 & 5 & 2 & 5 & 5 & + \\
\hline 44 & $43 / \mathrm{M}$ & Extremities & ND & 5 & 5 & 4 & ND & ND & ND & 5 & $4^{b}$ & 5 & + \\
\hline 45 & $80 / \mathrm{M}$ & Pleura & 4.4 & 3 & 4 & 3 & ND & ND & ND & $3^{\mathrm{b}}$ & 0 & 2 & + \\
\hline 46 & $47 / F$ & Pelvis & 1.5 & 3 & 4 & 3 & ND & ND & ND & 1 & 5 & 4 & ND \\
\hline 47 & $30 / \mathrm{M}$ & Head and neck & 3 & 5 & 5 & 1 & 4 & 5 & 5 & 4 & 4 & $4^{\mathrm{b}}$ & + \\
\hline 48 & $21 / \mathrm{F}$ & Abdomen & 5.5 & 3 & 4 & 4 & ND & ND & ND & 4 & $3^{\mathrm{b}}$ & 4 & + \\
\hline 49 & $71 / \mathrm{F}$ & Pleura & ND & 5 & 5 & 4 & ND & ND & ND & 4 & 4 & 5 & + \\
\hline
\end{tabular}


Table II. Continued.

Immunohistochemistry (proportion score)

\begin{tabular}{|c|c|c|c|c|c|c|c|c|c|c|c|c|c|}
\hline & & & & & & & & & & & & & \\
\hline No. & $\begin{array}{l}\text { ge (years)/ } \\
\text { gender }\end{array}$ & $\begin{array}{l}\text { Tumor } \\
\text { location }\end{array}$ & $\begin{array}{l}\text { Size } \\
(\mathrm{cm})\end{array}$ & $\begin{array}{c}\text { STAT6 } \\
\text { (nuclear) }\end{array}$ & $N A B 2$ & $C D 34$ & $A L D H 1^{\mathrm{a}}$ & $G R I A 2^{\mathrm{a}}$ & $I G F 2^{\mathrm{a}}$ & $C D 99$ & $B C L 2$ & $L S D 1$ & $\begin{array}{c}\text { in situ } \\
\text { PLA }\end{array}$ \\
\hline 50 & $34 / \mathrm{M}$ & Head and neck & ND & 3 & 3 & 4 & ND & ND & ND & 0 & 2 & 2 & + \\
\hline 51 & $59 / \mathrm{M}$ & Pleura & $\mathrm{ND}$ & 4 & 5 & 4 & ND & ND & ND & 4 & 3 & 4 & + \\
\hline 52 & $66 / \mathrm{M}$ & Lung & 5 & 5 & 5 & 5 & ND & ND & ND & $3^{\mathrm{b}}$ & 4 & 4 & + \\
\hline 53 & $83 / \mathrm{F}$ & Thorax & 14 & 5 & 5 & 5 & ND & ND & ND & 4 & 2 & 4 & + \\
\hline 54 & $71 / \mathrm{M}$ & Lung & 2.8 & 4 & 4 & 5 & ND & ND & ND & $3^{\mathrm{b}}$ & 3 & 4 & + \\
\hline 55 & $66 / \mathrm{F}$ & Mesenterium & 18 & 4 & 4 & 2 & ND & ND & ND & 5 & 5 & 5 & + \\
\hline 56 & $65 / M$ & Prostate & 3.5 & 4 & 4 & 3 & ND & ND & ND & 5 & 5 & 5 & + \\
\hline 57 & $80 / \mathrm{M}$ & Abdomen & 10 & 5 & 5 & 5 & ND & ND & ND & $4^{b}$ & 5 & 5 & + \\
\hline 58 & $75 / \mathrm{F}$ & Thorax & $\mathrm{ND}$ & 4 & 4 & 2 & ND & ND & ND & 3 & 2 & 3 & + \\
\hline 59 & $26 / \mathrm{F}$ & Pelvis & 5 & 4 & 4 & 3 & ND & ND & ND & 0 & $5^{\mathrm{b}}$ & $4^{\mathrm{b}}$ & + \\
\hline 60 & $33 / \mathrm{F}$ & Head and neck & $\mathrm{ND}$ & 4 & 4 & 4 & ND & ND & ND & 0 & 3 & 0 & + \\
\hline 61 & $71 \mathrm{M}$ & Pleura & 16 & 4 & 4 & 3 & ND & ND & ND & 0 & 5 & 3 & + \\
\hline 62 & $50 / \mathrm{F}$ & Abdomen & 8.8 & 4 & 4 & 5 & ND & ND & ND & 5 & 2 & 5 & + \\
\hline 63 & $76 / \mathrm{M}$ & Lung & 2 & 5 & 5 & 5 & ND & ND & ND & 0 & 4 & 4 & + \\
\hline 64 & $56 / \mathrm{F}$ & Pelvis & 8 & 5 & 5 & 5 & ND & ND & ND & 5 & 5 & 5 & + \\
\hline 65 & $82 / \mathrm{M}$ & Pelvis & 6 & 4 & 4 & 5 & ND & ND & ND & 5 & 5 & 5 & + \\
\hline 66 & $57 / \mathrm{F}$ & Abdomen & 7.5 & 5 & 5 & 5 & ND & ND & ND & 2 & 4 & 5 & + \\
\hline 67 & $60 / \mathrm{F}$ & Pelvis & 17 & 3 & 3 & 5 & ND & ND & ND & 0 & 4 & 5 & - \\
\hline 68 & $56 / \mathrm{M}$ & Abdomen & 9.5 & 4 & 4 & 5 & ND & ND & ND & 0 & 4 & 5 & + \\
\hline 69 & $41 / M$ & Abdomen & 2.8 & 5 & 5 & 5 & ND & ND & ND & $3^{\mathrm{b}}$ & 4 & 4 & + \\
\hline 70 & $92 / \mathrm{F}$ & Pleura & 2.2 & 5 & 5 & 5 & ND & ND & ND & 4 & $3^{\mathrm{b}}$ & 5 & + \\
\hline 71 & $74 / \mathrm{M}$ & Pelvis & ND & 4 & 4 & 2 & ND & ND & ND & 0 & 4 & $4^{\mathrm{b}}$ & + \\
\hline 72 & $67 / F$ & Abdomen & 12.4 & 3 & 3 & 5 & ND & ND & ND & 0 & 4 & 4 & + \\
\hline 73 & $67 / \mathrm{M}$ & Head and neck & 4.5 & 5 & 5 & 5 & ND & ND & ND & 0 & 4 & 4 & + \\
\hline 74 & $40 / \mathrm{M}$ & Head and neck & 10 & 5 & 5 & 5 & ND & ND & ND & 0 & 5 & 5 & + \\
\hline 75 & $68 / \mathrm{F}$ & Retroperitoneum & 6.2 & 5 & 5 & 5 & ND & ND & ND & 0 & 4 & 5 & + \\
\hline 76 & $61 / F$ & Pleura & 12 & 5 & 4 & $3^{b}$ & ND & ND & ND & 0 & 5 & 4 & + \\
\hline 77 & $74 / F$ & Pleura & 10.4 & 3 & 3 & 5 & ND & ND & ND & 0 & 5 & 5 & + \\
\hline 78 & $73 / \mathrm{M}$ & Lung & 11 & 5 & 5 & 5 & ND & ND & ND & 0 & 5 & 5 & + \\
\hline 79 & $75 / \mathrm{M}$ & Lung & 8 & 5 & 5 & 4 & ND & ND & ND & 0 & 5 & 5 & + \\
\hline 80 & $74 / \mathrm{M}$ & Pleura & 12.5 & 4 & 4 & 3 & ND & ND & ND & 2 & 5 & 5 & + \\
\hline
\end{tabular}

F, female; M, male; ND, not determined; PLA, proximity ligation assay. IHC staining was scored as follows: 0 , no positive cells, $1,<1 \% ; 2$,

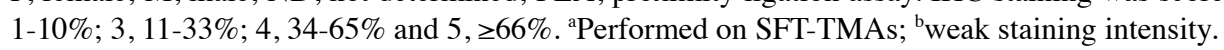

GRIA2) followed by ii) incubation with respective primary antibodies $\left(37^{\circ} \mathrm{C}\right.$ for $\left.30 \mathrm{~min}\right)$ and iii) employment of the BrightVision+ histostaining detection system (Poly-HRP-anti $\mathrm{Ms} / \mathrm{Rb}$ /Rt IgG, DPVB999HRP; ImmunoLogic, Duiven, The Netherlands) according to the manufacturer's instructions (RT, 15 min). Staining with CD34, CD99, BCL2 and LSD1 was performed on a routine diagnostic Leica Bond-Max IHC system (Leica Biosystems, Nussloch, Germany) using standard protocols. Cytoplasmic and nuclear immunoreactivity was scored combining: i) staining intensity ( 0 , non-existent; 1 , weak; 2, moderate; and 3, strong) and ii) staining proportion ( 0 , no staining; $1,<1 \%$ positive cells; $2,1-10 \%$ positive cells; $3,11-33 \%$ positive cells; $4,34-65 \%$ positive cells; and $5, \geq 66 \%$ positive cells). Only cases with moderate to strong staining in
$>10 \%$ cells (proportion score $>2$ ) were considered positive for the purposes of the study.

Duolink in situ proximity ligation assay (PLA). Sections from FFPE blocks $(4 \mu \mathrm{m})$ were processed according to the Duolink PLA manufacturer's brightfield instructions (Duo92012; Sigma-Aldrich, St. Louis, MO, USA). In brief: i) pretreatment using EDTA ( $\mathrm{pH} 8.0$ ) for $25 \mathrm{~min}$ at $100^{\circ} \mathrm{C}$, followed by ii) peroxidase quenching and blocking, incubation with iii) the identical primary NAB2 and STAT6 antibodies as used for immunohistochemistry (1:100 and 1:400 dilution, respectively) at $37^{\circ} \mathrm{C}$ for $30 \mathrm{~min}$; and iv) secondary antibodies (PLA probe PLUS and MINUS, conjugated with oligonucleotides); v) enzymatic ligation depending on the close proximity of the 

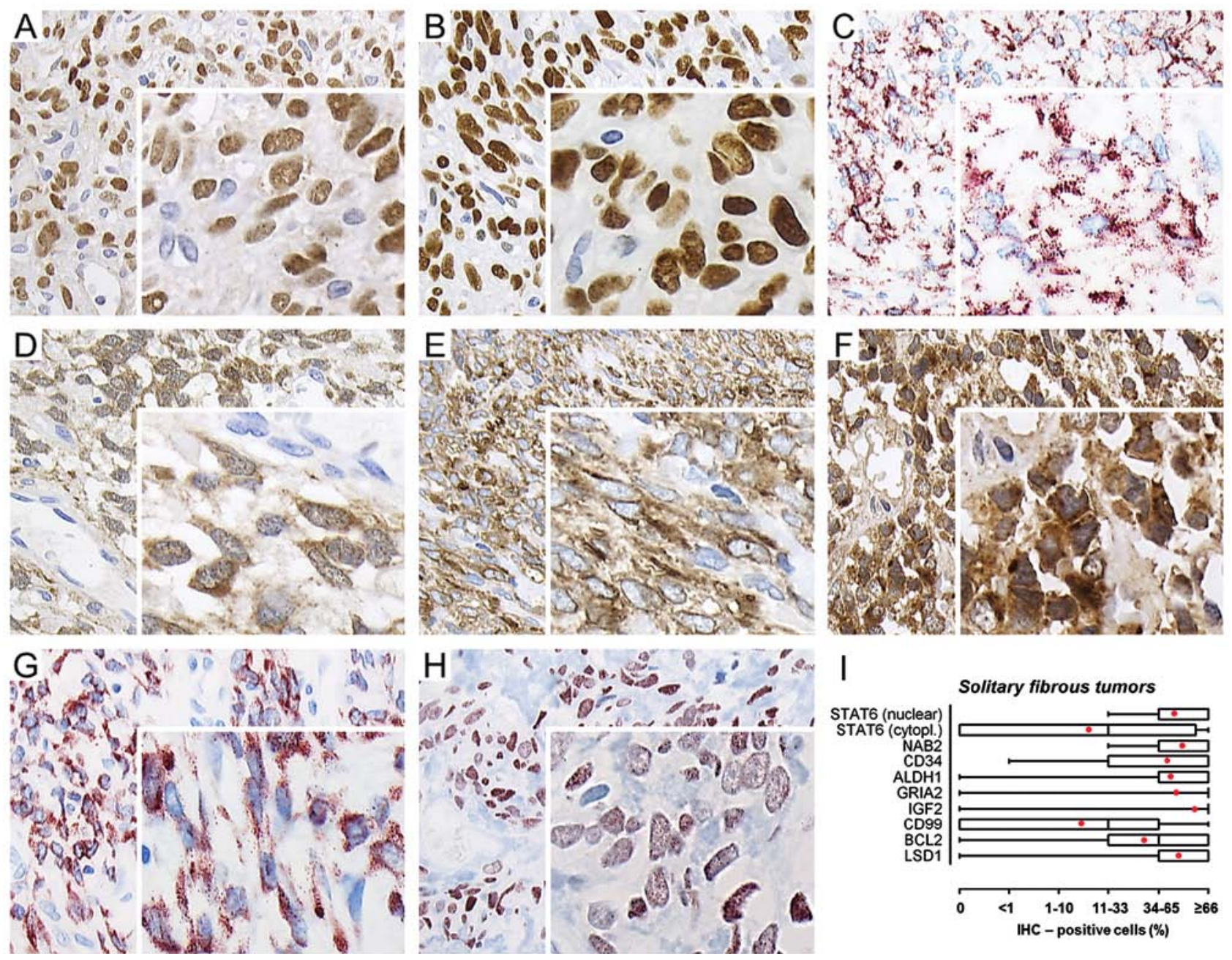

Figure 1.Immunohistochemical spectrum of SFTs. Immunohistochemical analyses of representative SFT tissue sections, demonstrating expression of (A) nuclear STAT6, (B) NAB2, (C) CD34, (D) ALDH1, (E) GRIA2, (F) IGF2, (G) BCL2 and (H) LSD1 (original magnification, x20, inset x40). (I) Immunohistochemical spectrum of 80 SFTs summarized as box plots (shown are whiskers from minimum to maximum, 25th percentile, median and 75th percentile; red dot represents the mean).

PLA probes PLUS and MINUS $\left(37^{\circ} \mathrm{C}\right.$ for $\left.30 \mathrm{~min}\right)$; vii) circle amplification $\left(37^{\circ} \mathrm{C}\right.$ for $\left.120 \mathrm{~min}\right)$; and viii) terminal detection and nuclear counterstaining. Evaluation of the processed slides was performed using a Leica DMLB brightfield microscope.

\section{Results}

STAT6, NAB2, ALDH1, GRIA2 and IGF2 immunohistochemistry. Initially, SFT sections were stained with conventional immunohistochemical markers, indicating a non-specific SFT profile: CD34 was expressed in 70/80 (88\%; Fig. 1C), BCL2 in 57/80 (71\%; Fig. 1G), LSD1 in 71/80 (89\%; Fig. 1H) and CD99 in 33/80 (41\%) SFT samples (Tables II and III). Furthermore, the diagnostic values of nuclear and cytoplasmic STAT6 expression were evaluated. In summary, 80/80 (100\%) SFT samples demonstrated a distinctive moderate to strong nuclear staining pattern (Figs. 1A and 2) and 8/80 (10\%) SFTs showed cytoplasmic staining of moderate intensity. To investigate the expression of STAT6 in a comprehensive fraction of other mesenchymal tumors, we additionally stained 385 non-SFT soft tissue tumors including malignant and benign neoplasms (374 tumors could be evaluated on 11 different TMAs, summarized in Table III). Positive nuclear
STAT6 staining was noted in a minor fraction of 4/374 (1\%) non-SFTs, including well-differentiated liposarcomas (2/75), dedifferentiated liposarcoma (1/72) and synovial sarcoma (1/15) cases (Fig. 3). Restricted cytoplasmic STAT6 expression was heterogeneously intense and present across all tumor entities. Thus, nuclear positivity for STAT6 was found highly specific (SP) and sensitive (SE) for the diagnosis of SFT vs. other mesenchymal tumors (SP, 99\%; PPV 95\%; Table IV).

We next analyzed the diagnostic value of NAB2 expression. A total of 80 out of $80(100 \%)$ SFTs showed positive NAB2 staining (Figs. 1B and 2), compared to a considerable fraction of other mesenchymal soft tissue tumors: 14/29 (48\%) angiosarcomas, 27/72 (38\%) dedifferentiated liposarcomas, $4 / 6(67 \%)$ hemangiomas, 14/68 (21\%) leiomyosarcomas, $11 / 24$ (46\%) malignant peripheral nerve sheath tumors, 20/29 (69\%) myxoid liposarcomas, 2/9 (22\%) pleomorphic liposarcomas, 11/12 (92\%) schwannomas, 7/15 (47\%) synovial sarcomas, 13/35 (37\%) undifferentiated pleomorphic sarcomas and 23/75 (31\%) well-differentiated liposarcomas showed positive stainings for NAB2 (Table III). In contrast to nuclear STAT6, no significant distinction in the differential diagnosis of SFTs was observed for the expression of NAB2 (SP, 61\%; PPV 35\%; Table IV). 
Table III. Immunohistochemistry results of 454 soft tissue tumors.

\begin{tabular}{|c|c|c|c|c|c|c|}
\hline \multirow[b]{3}{*}{ Tumor type } & \multicolumn{6}{|c|}{ Immunohistochemistry-positive (\%) } \\
\hline & \multicolumn{2}{|c|}{ STAT6 } & \multirow[b]{2}{*}{$N A B 2$} & \multirow[b]{2}{*}{$A L D H 1^{\mathrm{a}}$} & \multirow[b]{2}{*}{ GRIA2 } & \multirow[b]{2}{*}{$I G F 2$} \\
\hline & Nuclear & Cytoplasmic & & & & \\
\hline Angiosarcoma & $0(0)$ & $3(10)$ & $14(48)$ & $0(0)$ & $1(3)$ & $16(55)$ \\
\hline Dedifferentiated liposarcoma & $1(1)$ & $8(11)$ & $27(38)$ & $0(0)$ & $3(4)$ & $27(38)$ \\
\hline Hemangioma & $0(0)$ & $2(33)$ & $4(67)$ & ND & $0(0)$ & $2(33)$ \\
\hline Leiomyosarcoma & $0(0)$ & $3(4)$ & $14(21)$ & $0(0)$ & $22(32)$ & $29(43)$ \\
\hline Malignant peripheral nerve sheath tumor & $0(0)$ & $0(0)$ & $11(46)$ & $0(0)$ & $1(4)$ & $7(29)$ \\
\hline Myxoid liposarcoma & $0(0)$ & $1(3)$ & $20(69)$ & $0(0)$ & $0(0)$ & $3(10)$ \\
\hline Pleomorphic liposarcoma & $0(0)$ & $1(11)$ & $2(22)$ & $0(0)$ & $0(0)$ & $3(33)$ \\
\hline Schwannoma & $0(0)$ & $0(0)$ & $11(92)$ & ND & $0(0)$ & $1(8)$ \\
\hline Solitary fibrous tumor & $80(100)$ & $8(10)$ & $80(100)$ & $25(76)$ & $21(64)^{\mathrm{a}}$ & $25(76)^{\mathrm{a}}$ \\
\hline Synovial sarcoma & $1(7)$ & $2(13)$ & $7(47)$ & $0(0)$ & $3(20)$ & $7(47)$ \\
\hline Undifferentiated pleomorphic sarcomas & $0(0)$ & $0(0)$ & $13(37)$ & $0(0)$ & $0(0)$ & $7(20)$ \\
\hline Well-differentiated liposarcoma & $2(3)$ & $5(7)$ & $23(31)$ & ND & $0(0)$ & $40(55)$ \\
\hline
\end{tabular}

ND, not determined; $>10 \%$ moderate to strong nuclear/cytoplasmic staining was considered positive for the purposes of the study; aperformed on individual TMAs comprising SFT ( $\mathrm{n}=33$ evaluated) and pan-soft tissue tumor specimens ( $\mathrm{n}=44$ evaluated).

Table IV. Differential value of STAT6, NAB2, ALDH1, GRIA2 and IGF2 immunohistochemistry for the diagnosis of SFT vs. other mesenchymal soft tissue tumors.

\begin{tabular}{|c|c|c|c|c|c|c|c|c|}
\hline IHC marker & SE & $\mathrm{Cl} 95 \%$ & SP & $\mathrm{Cl} 95 \%$ & PPV & $\mathrm{Cl} 95 \%$ & NPV & $\mathrm{Cl} 95 \%$ \\
\hline $\begin{array}{l}\text { STAT6+ (nuclear) } \\
\text { SFT }(n=80 / 80) \\
\text { Non-SFT }(n=3 / 374)\end{array}$ & $100 \%$ & $0.94-1.00$ & $98.9 \%$ & $0.97-0.99$ & $95.2 \%$ & $0.87-0.98$ & $100 \%$ & $0.98-1.00$ \\
\hline $\begin{array}{l}\text { STAT6+ (cytoplasmic) } \\
\text { SFT }(n=8 / 80) \\
\text { Non-SFT }(n=25 / 374)\end{array}$ & $10.0 \%$ & $0.05-0.19$ & $93.3 \%$ & $0.90-0.96$ & $24.3 \%$ & $0.12-0.43$ & $82.9 \%$ & $0.79-0.86$ \\
\hline $\begin{array}{l}\text { NAB2+ } \\
\text { SFT }(n=80 / 80) \\
\text { Non-SFT }(n=146 / 374)\end{array}$ & $100 \%$ & $0.94-1.00$ & $60.9 \%$ & $0.56-0.66$ & $35.4 \%$ & $0.29-0.42$ & $100 \%$ & $0.98-1.00$ \\
\hline $\begin{array}{l}\text { ALDH1+ } \\
\text { SFT }(n=25 / 33)^{\mathrm{a}} \\
\text { Non-SFT }(n=2 / 44)^{\mathrm{a}}\end{array}$ & $75.8 \%$ & $0.57-0.88$ & $95.5 \%$ & $0.83-0.99$ & $92.5 \%$ & $0.74-0.99$ & $84 \%$ & $0.70-0.92$ \\
\hline $\begin{array}{l}\text { GRIA2+ } \\
\text { SFT }(n=21 / 33)^{\mathrm{a}} \\
\text { Non-SFT }(n=30 / 374)\end{array}$ & $63.6 \%$ & $0.45-0.79$ & $92.0 \%$ & $0.89-0.94$ & $41.2 \%$ & $0.28-0.56$ & $96.7 \%$ & $0.94-0.98$ \\
\hline $\begin{array}{l}\text { IGF2+ } \\
\text { SFT }(n=25 / 33)^{\mathrm{a}} \\
\text { Non-SFT }(n=142 / 374)\end{array}$ & $75.8 \%$ & $0.57-0.88$ & $62.0 \%$ & $0.57-0.67$ & $15.0 \%$ & $0.10-0.22$ & $96.7 \%$ & 0.93-0.98 \\
\hline
\end{tabular}

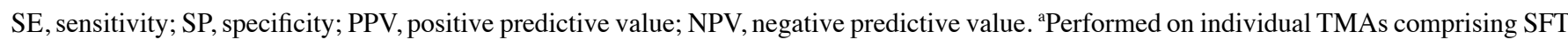
$(\mathrm{n}=33$ evaluated) and pan-soft tissue tumor specimens ( $\mathrm{n}=44$ evaluated).

To investigate novel putative markers of SFTs, we further assessed ALDH1 expression in different mesenchymal soft tissue tumors including 33 SFT cases (individual SFT TMA) and 44 non-SFT neoplasms (pan-soft tissue tumors TMA, 4 different cases per tumor entity) comprising: angiosarcomas, dedifferentiated liposarcomas, leiomyosarcomas, malignant 

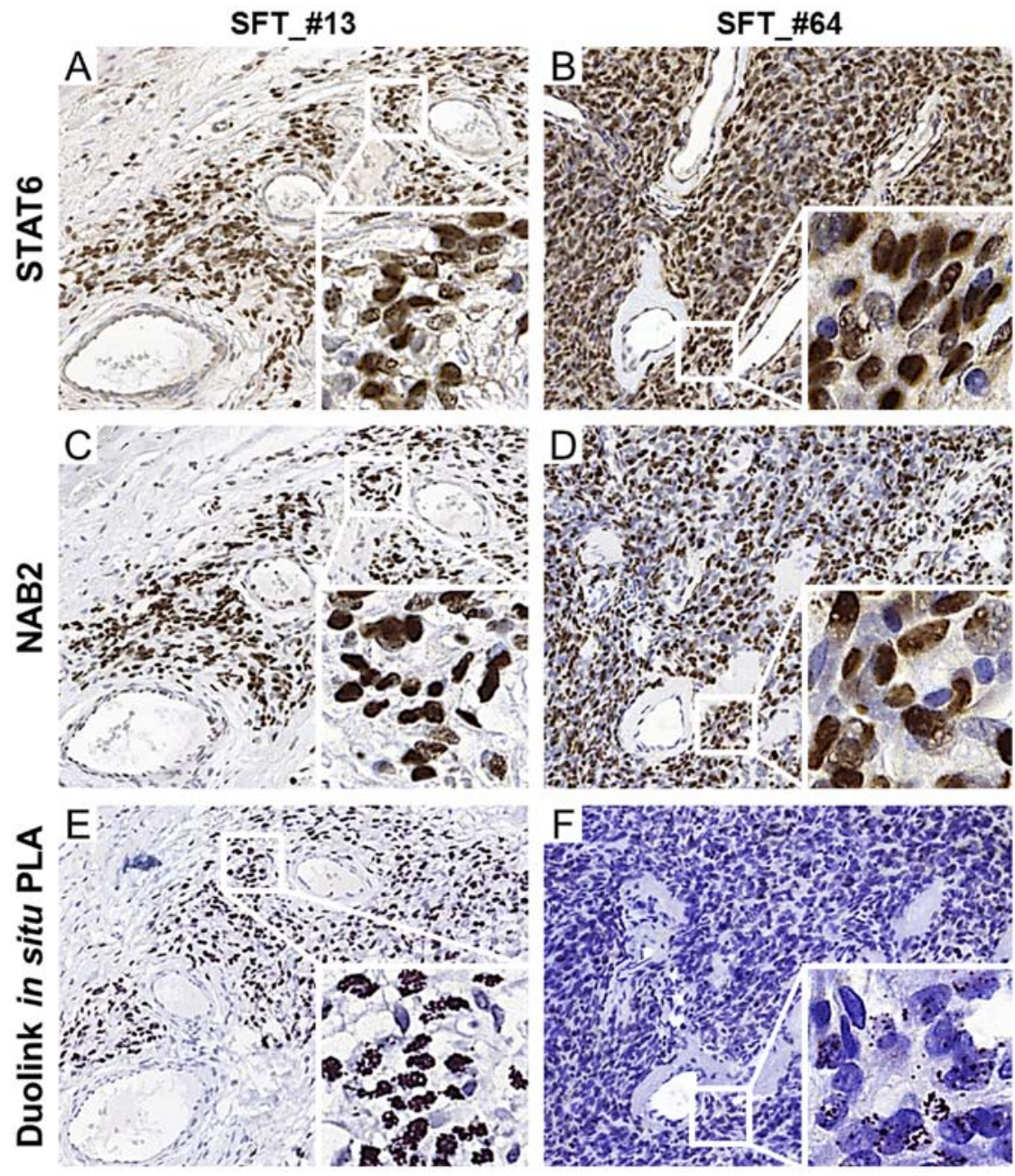

Figure 2. Positive NAB2-STAT6 Duolink in situ PLA assay in SFTs. Immunohistochemical stainings showing strong nuclear expression of (A-B) STAT6 and (C-D) NAB2 in two representative SFT cases. (E-F) Multiple positive signals indicating the presence of NAB2-STAT6 fusion proteins by nuclear proximity of NAB2 and STAT6 (original magnification, x10, inset x40, detailed images as in Fig. 5).

peripheral nerve sheath tumors, myxoid liposarcomas, pleomorphic liposarcomas, synovial sarcomas, undifferentiated pleomorphic sarcomas, rhabdomyosarcoma, myxofibrosarcoma and endometrial stromal sarcoma. Cytoplasmic ALDH1 expression was present in 25/33 (76\%) SFT samples (Fig. 1D) and also observed in one case of rhabdomyosarcoma and endometrial stromal sarcoma. Specificity and sensitivity for the diagnosis of SFT vs. other mesenchymal tumors was 96 and $76 \%$, respectively (Table IV).

GRIA2 expression was also investigated (individual SFT TMA and 374 other mesenchymal samples). A total of 21 out of 33 (64\%) SFTs (Fig. 1E), 1/29 (3\%) angiosarcomas, 3/72 (4\%) dedifferentiated liposarcomas, 0/6 (0\%) hemangiomas, 22/68 (32\%) leiomyosarcomas, 1/24 (4\%) malignant peripheral nerve sheath tumors, 0/29 (0\%) myxoid liposarcomas, 0/9 (0\%) pleomorphic liposarcomas, 0/12 (0\%) schwannomas, 3/15 (20\%) synovial sarcomas, $0 / 35(0 \%)$ undifferentiated pleomorphic sarcomas and 0/75 (0\%) well-differentiated liposarcomas showed high levels of cytoplasmic GRIA2 (SP, 92\%; SE, 64\%; PPV, 41\%; Table IV).

In addition, IGF2 expression was examined in 407 soft tissue tumors comprising 33 SFT cases (individual SFT TMA) and 374 non-SFT mesenchymal neoplasms. Cytoplasmic
IGF2 expression was observed in 25/33 (76\%) SFTs (Fig. 1F), $16 / 29(55 \%)$ angiosarcomas, 27/72 (38\%) dedifferentiated liposarcomas, 2/6 (33\%) hemangiomas, 29/68 (43\%) leiomyosarcomas, $7 / 24$ (29\%) malignant peripheral nerve sheath tumors, 3/29 (10\%) myxoid liposarcomas, 3/9 (33\%) pleomorphic liposarcomas, 1/12 (8\%) schwannomas, 7/15 (47\%) synovial sarcomas, $7 / 35$ (20\%) undifferentiated pleomorphic sarcomas and 40/75 (55\%) well-differentiated liposarcomas (Table III). No significant difference was noted comparing the SE (76\%) and SP (62\%) of IGF2 expression for the diagnosis of SFT (PPV, 15\%; Table IV). All individual SFT results are summarized in Table II.

Duolink proximity ligation assay (PLA) in SFTs. Presence of the NAB2-STAT6 fusion protein was indicated based on the Duolink in situ proximity ligation brightfield assay and supported by nuclear STAT6-NAB2 IHC stainings. Positive signals were observed in 71/78 (91\%) SFT cases (two cases failed to be processed due to the lack of remaining FFPE material), providing highly suggestive evidence for the proximate co-localization of STAT6 and NAB2 antigens within a distance of $\sim 30 \mathrm{~nm}$ (Fig. 4A). In contrast to positive STAT6 and NAB2 nuclear immunoreactivity, no evidence for the pres- 

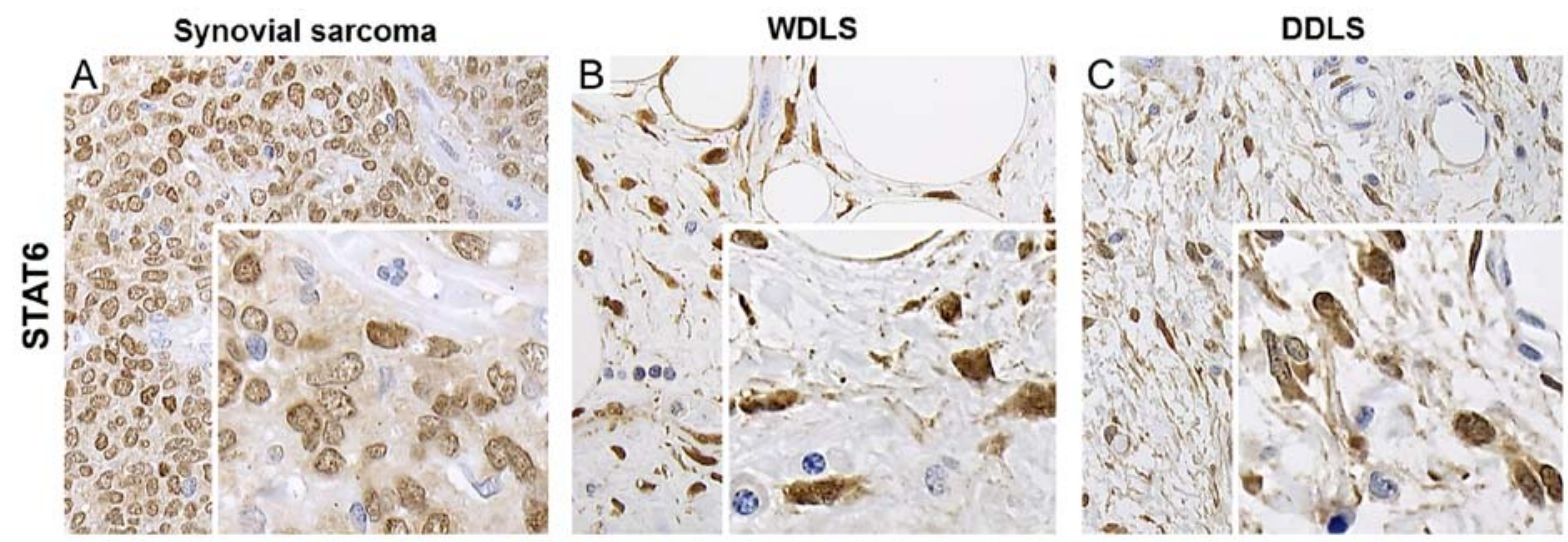

Figure 3. Nuclear expression of STAT6 in non-SFT cases. Moderate to strong nuclear STAT6 staining in one case of (A) synovial sarcoma (B) well-differentiated liposarcoma and (C) dedifferentiated liposarcoma (original magnification, $\mathrm{x} 20$, inset $\mathrm{x} 40$ ).

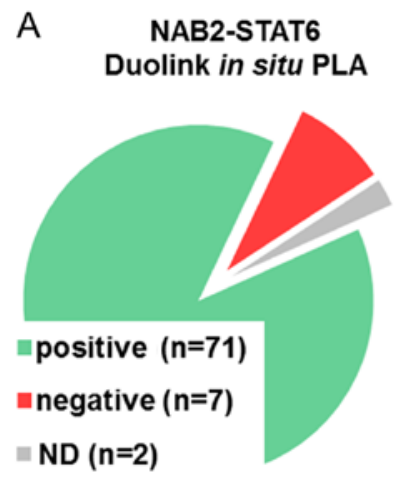
B Immunohistochemistry and Duolink in situ PLA assay in solitary fibrous tumors

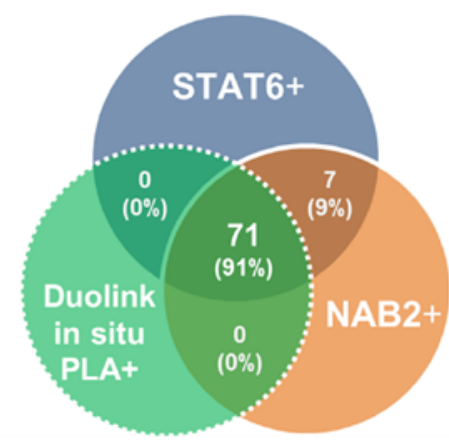

Figure 4. Duolink in situ PLA assay in SFTs. (A) Overall NAB2-STAT6 nuclear proximity in SFTs. (B) Venn diagram indicating the concordance between immunohistochemistry results (solid circles; nuclear STAT6/NAB2 staining) and the Duolink in situ PLA assay (dashed circle). In total, 71 (91\%) SFT cases were positive in all three analyses (Table II). Incomplete concordance between IHC and Duolink in situ PLA results was observed for 7 cases (9\%). Due to lack of remaining FFPE material, 2 cases could not be determined.

ence of NAB2-STAT6 fusion proteins was recognized in 7/78 (9\%) SFT cases. The concordance of nuclear STAT6/NAB2 IHC staining results and the Duolink in situ proximity ligation assay is summarized in Fig. 4B and indicated in Figs. 2 and 5.

Expression of STAT6, ALDH1 and GRIA2 in different tumor derived cell lines. Expression levels of STAT6, ALDH1 and GRIA2 were additionally examined in total protein extracts from primary SFT tumor tissues and non-SFT-derived cell lines by immunoblotting (Fig. 6). Total STAT6 expression was heterogeneously intense and observed across all cell lines (with only limited levels of total STAT6 in gastrointestinal stromal tumors). In contrast, GRIA2 and ALDH1 expression was mainly detectable in two primary SFT tumor tissue samples and singularly in one GIST derived cell line (GIST48).

\section{Discussion}

Solitary fibrous tumor is a mesenchymal neoplasm which can arise from any organ in the body (2). Aggressive behavior has been reported in up to $10 \%$ of SFT cases depending on tumor location, size and mitotic activity $(4,16,17)$. Presenting as a painless mass is the main manifestation of this tumor, however, some patients suffer from hypoglycemia as a paraneoplastic syndrome the so-called Doege-Potter syndrome. Besides standard H\&E morphology, CD34, CD99, BCL2 and LSD1 are supportive immunohistochemistry markers which can help to diagnose this tumor but are of low specificity $(4,18)$. As the histomorphological spectrum of SFT is wide, the list of possible diagnostic pitfalls is long. Until recently, the genomic background of SFT was poorly understood and reliable specific immunohistochemical markers were missing. Recent findings showed the fusion of NAB2 and STAT6 on chromosome 12 in the majority of SFT. Robinson et al (10) reported NAB2-STAT6 gene fusions in 51/51 (100\%) SFT cases using whole exome sequencing. This fusion has also been found using transcriptome sequencing in 29/53 (54.7\%) SFT cases by Chmielecki et al (9). RT-PCR showed NAB2-STAT6 fusions in 37/41 (90.2\%) cases of SFT in another study (14). It has been shown that there are various breakpoints in the NAB2 and STAT6 gene. Breaking in the STAT6 gene occurs within, or in the $\mathrm{N}$-terminal to the Src homology domain. Thus, the transcriptional activator domain will be preserved in the fused state. Since NAB2 exchanges its repressor domain with the transcriptional activator of STAT6 and its breakpoint 


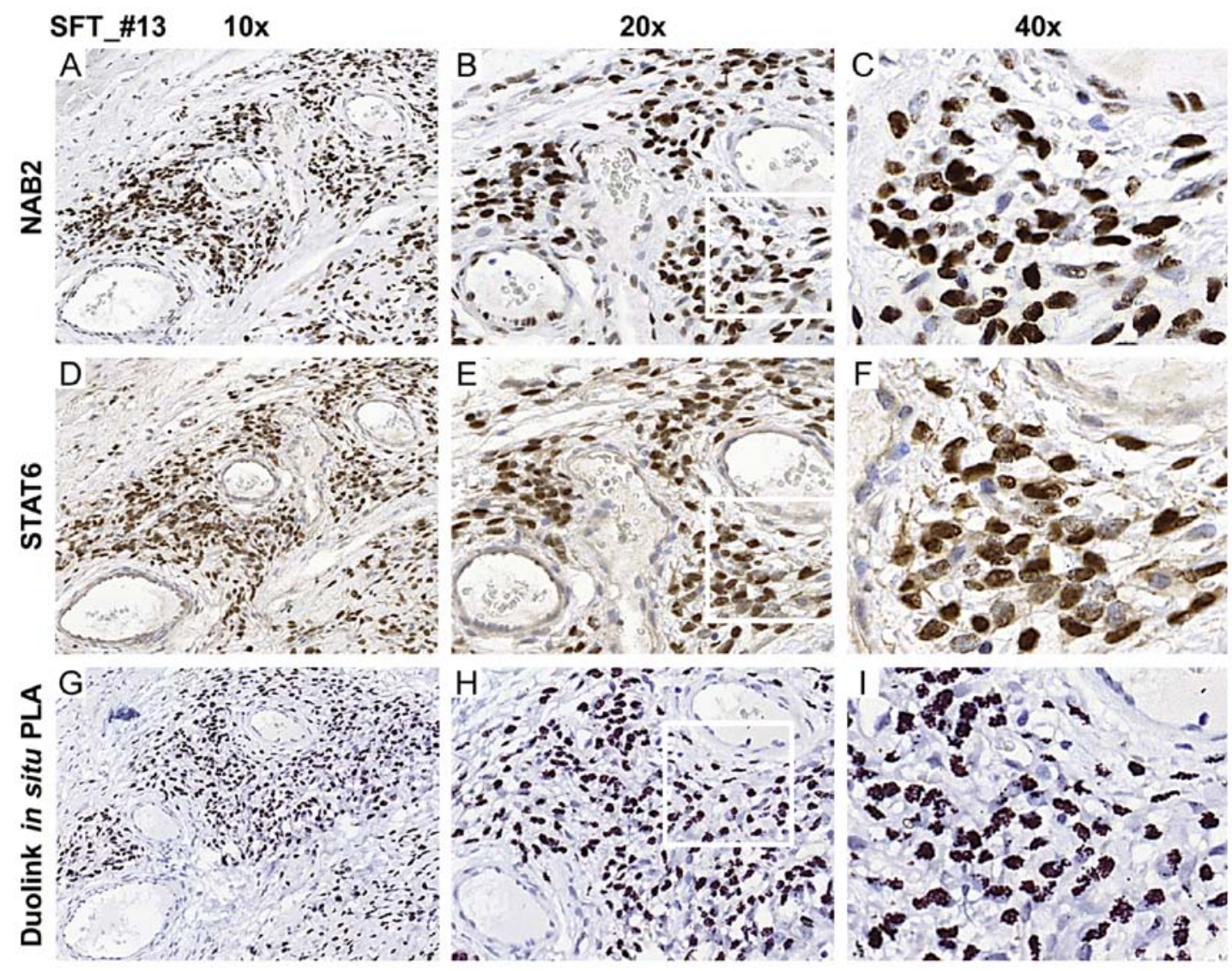

Figure 5. Comparison of NAB2/STAT6 immunohistochemistry and Duolink in situ PLA assay in a representative SFT case. Immunohistochemical staining showing expression and nuclear localization of (A-C) NAB2 and (D-F) STAT6 in a representative SFT case (SFT_\#13). (G-I) Multiple positive signals demonstrating the presence of NAB2-STAT6 fusion proteins by nuclear proximity of NAB2 and STAT6 (original magnification, x10-40 as indicated).

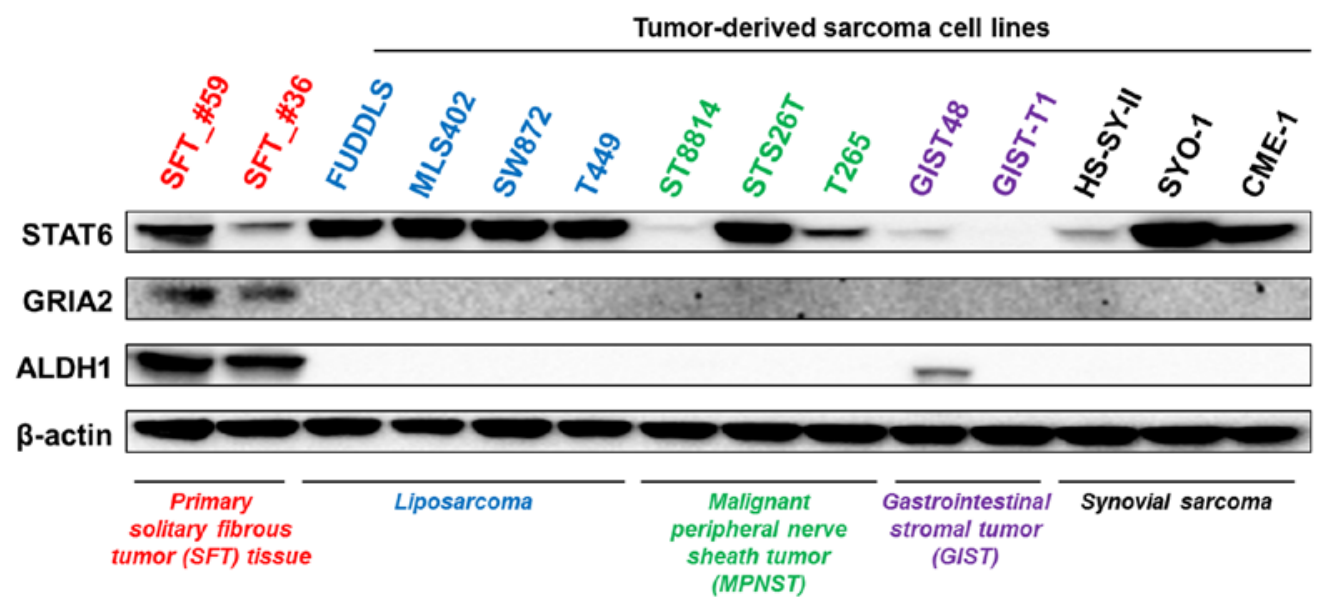

Figure 6. Expression of STAT6, ALDH1 and GRIA2 in different soft tissue tumors. Immunoblotting comparing expression of STAT6, GRIA2 and ALDH1 in total protein extracts of primary SFT tumor tissues and different well-defined sarcoma cell lines.

is C-terminal to the nuclear localization signal, the obtained fused protein has a nuclear localization possessing a transcriptional activity (19).

Schweizer et al (19) detected nuclear STAT6 expression in 25/25 meningeal SFTs and 35/37 meningeal hemangiopericytomas while 86/87 meningiomas expressed STAT6 only in the cytoplasm. Another recent study reported only nuclear expression of STAT6 in 59/60 SFTs obtained from other organs. A total of 4 out of 171 cases of their chosen histologic mimics of SFT (including 3/21 dedifferentiated liposarcomas and 1/10 deep fibrous histiocytomas) showed nuclear STAT6 expression based on the quantity of the positive tumor cells in IHC sections (20). Sugita et al (21) compared STAT6 immunohistochemistry of different fibrovascular tumors including 26 SFTs which were all strongly positive for STAT6. A study of Yoshida et al (22) with 49 SFTs also confirmed the positivity in all their cases whereas only 4/159 non-SFT exhibited a weak nuclear STAT6 expression. 
We observed nuclear STAT6 expression in all 80 SFT cases and additional cytoplasmic STAT6 expression in 8 tumors which is in line with previous findings. Notably, we observed nuclear STAT6 expression in 4 non-SFT mesenchymal tumors comprising: well-differentiated liposarcomas (2/75), dedifferentiated liposarcoma (1/72) and synovial sarcoma (1/15). The observation of nuclear STAT6 expression in liposarcomas was first described by Doyle et al (20) with 3/4 non-SFT STAT6 nuclear-positive samples belonging to the group of dedifferentiated liposarcomas. Shortly thereafter, STAT6 amplification (STAT6 gene is located on chromosome 12 adjacent to MDM2 and CDK4) was demonstrated in a subset of liposarcomas, suggestively explaining why a subgroup of liposarcomas may express high levels of nuclear STAT6 (23). However, the role of STAT6 in these liposarcomas and its potential transcriptional activity has to be clarified in further studies. As dedifferentiated liposarcomas may also express CD34 and may present with a hemangiopericytoma-like growth pattern, detection of MDM2 amplification helps to identify dedifferentiated liposarcomas from SFTs.

In the present study, NAB2 was expressed at high levels in all SFT cases and also in a large number of non-SFT soft tissue tumors. We conclude that this marker lacks specificity as additional diagnostic marker. To evaluate the relevance of potential target genes of the NAB2-STAT6 fusion protein, we further evaluated IGF2 expression. Robinson et al (10) have indicated that the NAB2-STAT6 fusion protein can induce expression of EGR1 targeted genes (e.g. IGF2). Furthermore, they showed expression of IGF2 also in an SFT cell line expressing the chimeric NAB2-STAT6 fusion protein. We detected expression of IGF2 in 25/33 SFT cases and 142/374 evaluated mesenchymal tumors. Besides, Steigen et al (24) showed SFT to express the highest level of IGF2 (80\%) among their evaluated panel of mesenchymal tumors including MPNST (50\%), SS (40\%), MLS (40\%) and UPS (30\%). Notably, IGF2-induced hypoglycemia has been observed not only in SFTs but also in other mesenchymal tumors such as fibrosarcoma/fibroma (23\%) and mesothelioma (8\%) (25). For diagnostic purpose, IGF2 expression is not specific enough to support diagnosis of SFT.

In several recent studies, GRIA2 has been shown to be upregulated in SFT samples $(14,26)$. We detected expression of GRIA2 in $64 \%$ of SFT cases, which is comparable to the study by Vivero et al (27). We also found GRIA2 to be expressed in other mesenchymal tumors such as leiomyosarcomas (22/68), synovial sarcomas (3/15), angiosarcomas (1/29) and malignant peripheral nerve sheath tumors (1/24). GRIA2 specificity and sensitivity for the diagnosis of SFTs versus other mesenchymal tumors was $92 \%$ and $64 \%$, respectively. Unlike the study of Vivero et al (27) which showed dedifferentiated liposarcoma not to express GRIA2, we have detected GRIA2 expression in 3/72 (4.2\%) dedifferentiated liposarcomas.

In the present study, ALDH1 expression was detected in $76 \%$ of SFTs. This finding is similar to a study conducted by Bouvier et al (15). Additionally, they reported positive ALDH1 stainings in 2/163 cases of meningioma and 7/98 cases of synovial sarcoma which should be distinguished from solitary fibrous tumors of the meninges. As only 2/44 non-SFT cases showed expression of ALDH1, detection of ALDH1 may be of diagnostic help in SFT (SE, 76\%; SP, 96\%; PPV, 93\% and NPV, 84\%). Taken together, on the immunohistochemical level, ALDH1 could be introduced as both relatively sensitive and specific markers for SFT, whereas NAB2 and IGF2 are expressed in a large number of different non-SFT and conclusively not specific enough. In summary, nuclear expression of STAT6 is the most specific diagnostic immunohistochemical marker of SFT.

Overall, the Duolink proximity ligation assay is a useful molecular technique for the detection of NAB2-STAT6 fusion proteins, with the vast majority of SFT cases (71/78 cases; 91\%) shown to be positive for the proximate co-localization of STAT6 and NAB2 antigens. However, 7 SFT cases without positive PLA signals indicate: i) that a subgroup of SFT will be under-diagnosed due to the negative reaction; and ii) this observation points to the possibility that not all SFTs which were clearly diagnosed by immunohistochemical markers carry the specific NAB2-STAT6 translocation subtypes. One explanation might be that the specific antigens may be truncated due to a different translocation subtype (28). Additionally, it cannot be ruled out that a subgroup of SFT may harbor other translocation types than those described until now.

In summary, we propose the following algorithm to establish a reliable diagnosis of SFTs: i) standard H\&E morphology with variable cellularity and high vascularity including the so-called staghorn thick wall vessels, combined with ii) immunohistochemistry for the detection of nuclear STAT6 (validated as the most specific and highly sensitive marker for SFTs), ALDH1 and CD34 positivity. As several NAB2-STAT6 translocation subtypes have been identified so far, further detailed evaluations concerning the prognostic and therapeutic impact have to be conducted. In this context, additional molecular analyses such as RT-PCR and/or Duolink in situ proximity ligation assays could further help to complement the diagnosis of SFTs. An established FISH assay is not available and with respect to routine clinical care, immunohistochemistry is superior to in situ proximity ligation assays to be applied in various pathology departments.

\section{Acknowledgements}

The present study was supported by the Deutsche Krebshilfe (KoSar grant no. 109742). S.O. was supported by the Heinrich Hertz foundation from the state of NRW. The authors are grateful to Magdalene Fielenbach and Wiebke Jeske for excellent technical assistance.

\section{References}

1. Briselli M, Mark EJ and Dickersin GR: Solitary fibrous tumors of the pleura: Eight new cases and review of 360 cases in the literature. Cancer 47: 2678-2689, 1981.

2. Gold JS, Antonescu CR, Hajdu C, Ferrone CR, Hussain M, Lewis JJ, Brennan MF and Coit DG: Clinicopathologic correlates of solitary fibrous tumors. Cancer 94: 1057-1068, 2002.

3. Vallat-Decouvelaere AV, Dry SM and Fletcher CD: Atypical and malignant solitary fibrous tumors in extrathoracic locations: Evidence of their comparability to intra-thoracic tumors. Am J Surg Pathol 22: 1501-1511, 1998.

4. Pathology and genetics of tumours of soft tissue and bone. In: World Health Organization Classification of Tumours. 4th edition. Fletcher CDM, Bridge JA, Hogendoorn P and Mertens F (eds). IARC Press, Lyon, 2013.

5. Demicco EG, Park MS, Araujo DM, Fox PS, Bassett RL, Pollock RE, Lazar AJ and Wang WL: Solitary fibrous tumor: A clinicopathological study of 110 cases and proposed risk assessment model. Mod Pathol 25: 1298-1306, 2012. 
6. Harrison-Phipps KM, Nichols FC, Schleck CD, Deschamps C Cassivi SD, Schipper PH, Allen MS, Wigle DA and Pairolero PC: Solitary fibrous tumors of the pleura: Results of surgical treatment and long-term prognosis. J Thorac Cardiovasc Surg 138: 19-25, 2009.

7. Park MS and Araujo DM: New insights into the hemangiopericytoma/solitary fibrous tumor spectrum of tumors. Curr Opin Oncol 21: 327-331, 2009.

8. Robinson LA: Solitary fibrous tumor of the pleura. Cancer Control 13: 264-269, 2006.

9. Chmielecki J, Crago AM, Rosenberg M, O'Connor R, Walker SR, Ambrogio L, Auclair D, McKenna A, Heinrich MC, Frank DA, et al: Whole-exome sequencing identifies a recurrent NAB2STAT6 fusion in solitary fibrous tumors. Nat Genet 45: 131-132, 2013.

10. Robinson DR, Wu YM, Kalyana-Sundaram S, Cao X, Lonigro RJ, Sung YS, Chen CL, Zhang L, Wang R, Su F, et al: Identification of recurrent NAB2-STAT6 gene fusions in solitary fibrous tumor by integrative sequencing. Nat Genet 45: 180-185, 2013.

11. Kumbrink J, Kirsch KH and Johnson JP: EGR1, EGR2, and EGR3 activate the expression of their coregulator NAB2 establishing a negative feedback loop in cells of neuroectodermal and epithelial origin. J Cell Biochem 111: 207-217, 2010.

12. Svaren J, Sevetson BR, Apel ED, Zimonjic DB, Popescu NC and Milbrandt J: NAB2, a corepressor of NGFI-A (Egr-1) and Krox 20, is induced by proliferative and differentiative stimuli. Mol Cell Biol 16: 3545-3553, 1996.

13. Goenka S and Kaplan MH: Transcriptional regulation by STAT6. Immunol Res 50: 87-96, 2011.

14. Mohajeri A, Tayebwa J, Collin A, Nilsson J, Magnusson L, von Steyern FV, Brosjö O, Domanski HA, Larsson O, Sciot R, et al: Comprehensive genetic analysis identifies a pathognomonic $N A B 2 / S T A T 6$ fusion gene, nonrandom secondary genomic imbalances, and a characteristic gene expression profile in solitary fibrous tumor. Genes Chromosomes Cancer 52: 873-886, 2013.

15. Bouvier C, Bertucci F, Métellus P, Finetti P, Maues de Paula A, Forest F, Mokhtari K, Miquel C, Birnbaum D, Vasiljevic A, et al: ALDH1 is an immunohistochemical diagnostic marker for solitary fibrous tumours and haemangiopericytomas of the meninges emerging from gene profiling study. Acta Neuropathol Commun 1: 10, 2013

16. Hasegawa T, Matsuno Y, Shimoda T, Hasegawa F, Sano T and Hirohashi S: Extrathoracic solitary fibrous tumors: Their histological variability and potentially aggressive behavior. Hum Pathol 30: 1464-1473, 1999.

17. Insabato L, Siano M, Somma A, Gentile R, Santangelo M and Pettinato G: Extrapleural solitary fibrous tumor: A clinicopathologic study of 19 cases. Int J Surg Pathol 17: 250-254, 2009.
18. Zafar $\mathrm{H}$, Takimoto $\mathrm{CH}$ and Weiss G: Doege-Potter syndrome: Hypoglycemia associated with malignant solitary fibrous tumor. Med Oncol 20: 403-408, 2003.

19. Schweizer L, Koelsche C, Sahm F, Piro RM, Capper D, Reuss DE, Pusch S, Habel A, Meyer J, Göck T, et al: Meningeal hemangiopericytoma and solitary fibrous tumors carry the NAB2-STAT6 fusion and can be diagnosed by nuclear expression of STAT6 protein. Acta Neuropathol 125: 651-658, 2013.

20. Doyle LA, Vivero M, Fletcher CD, Mertens F and Hornick JL: Nuclear expression of STAT6 distinguishes solitary fibrous tumor from histologic mimics. Mod Pathol 7: 390-395, 2013

21. Sugita S, Aoyama T, Kondo K, Keira Y, Ogino J, Nakanishi K, Kaya M, Emori M, Tsukahara T, Nakajima H, et al: Diagnostic utility of NCOA2 fluorescence in situ hybridization and Stat6 immunohistochemistry staining for soft tissue angiofibroma and morphologically similar fibrovascular tumors. Hum Pathol 45: 1588-1596, 2014.

22. Yoshida A, Tsuta K, Ohno M, Yoshida M, Narita Y, Kawai A, Asamura $\mathrm{H}$ and Kushima R: STAT6 immunohistochemistry is helpful in the diagnosis of solitary fibrous tumors. Am J Surg Pathol 38: 552-559, 2014.

23. Doyle LA, Tao D and Mariño-Enríquez A: STAT6 is amplified in a subset of dedifferentiated liposarcoma. Mod Pathol 27: 1231-1237, 2014

24. Steigen SE, Schaeffer DF, West RB and Nielsen TO: Expression of insulin-like growth factor 2 in mesenchymal neoplasms. Mod Pathol 22: 914-921, 2009.

25. Dynkevich Y, Rother KI, Whitford I, Qureshi S, Galiveeti S, Szulc AL, Danoff A, Breen TL, Kaviani N, Shanik MH, et al: Tumors, IGF-2, and hypoglycemia: Insights from the clinic, the laboratory, and the historical archive. Endocr Rev 34: 798-826, 2013.

26. Hajdu M, Singer S, Maki RG, Schwartz GK, Keohan ML and Antonescu CR: IGF2 over-expression in solitary fibrous tumours is independent of anatomical location and is related to loss of imprinting. J Pathol 221: 300-307, 2010.

27. Vivero M, Doyle LA, Fletcher CD, Mertens F and Hornick JL: GRIA2 is a novel diagnostic marker for solitary fibrous tumour identified through gene expression profiling. Histopathology 65 : 71-80, 2014

28. Barthelmeß S, Geddert H, Boltze C, Moskalev EA, Bieg M, Sirbu H, Brors B, Wiemann S, Hartmann A, Agaimy A, et al: Solitary fibrous tumors/hemangiopericytomas with different variants of the NAB2-STAT6 gene fusion are characterized by specific histomorphology and distinct clinicopathological features. Am J Pathol 184: 1209-1218, 2014. 